\title{
A Review of Teacher Thinking Researches
}

\author{
Mani Bhasin Kalra, Bharati Baveja, \\ University of Delhi, India
}

\begin{abstract}
Understanding teacher thinking and beliefs is important for improving teacher education courses and thereby school education. In India however, not much work in this area has been conducted/documented. This paper analyses a few of the studies conducted in the last 10 years in the area of Teacher Thinking Research. The studies conducted by various researchers, papers published, books and the like in Teacher Thinking/Teacher Beliefs are reviewed. In the end very few studies that have been conducted in India have been reviewed followed by findings and some insights gained from the review.
\end{abstract}

\section{Introduction}

"Beliefs and assumptions about teaching, whether in a school, or in any other context, are a direct reflection of the beliefs and assumptions the teacher holds about the learner and learning"[1]. In fact, teachers have implicit assumptions about knowledge, learning and learners- their epistemological assumptions. Researches in the area of Teacher Thinking propose that teacher thinking influences teachers' perceptions and the decisions that they take. These in turn, form teachers' beliefs that affect their performance in the classroom. "Beliefs may be defined as judgments and evaluations that we make about ourselves, about others, and about the world around us. Beliefs are generalizations about things such as causality or the meaning of specific actions....Beliefs not only affect how people behave but what they perceive in the environment. People perceive what they expect to perceive" [2]. Some researchers have called these beliefs "entering perspectives" or preconceptions. Beliefs are often mistaken as values, theories, perceptions etc. However, there still does not seem to be a consensus on the definition of 'Beliefs' or 'Personal Theories'.

Teacher's beliefs or teacher's personal theories may also be understood as what an individual teacher says, intends and does in the classroom. These beliefs or personal theories can be used to interpret and understand the significant influences on a teacher's decisions within the classroom. "Few would argue that the beliefs teachers hold influence their perceptions and judgments, which in turn affect their behaviour in the classroom, or that understanding the belief structures of teachers and teacher candidates is essential to improving their professional preparation and teaching practices"[3]. Beliefs are subjective theories and personal ideas about what we think are true about ourselves and the world around us. It has been emphasized that attention to the beliefs of teachers and teacher candidates should be a focus of educational research [4]. Beliefs can inform educational practice in ways that prevailing research agendas have not and cannot. It has been argued that teachers' beliefs can and should become an important focus of educational inquiry but that this will require clear conceptualizations, careful examination of key assumptions, consistent understandings and adherence to precise meanings, and proper assessment and investigation of specific belief constructs.

\section{Recent Studies}

Very few studies in India have been carried out in this area. A review of these studies indicates that they can broadly be classified into three broad categories: Teachers' Beliefs and Practices; Factors that Influence Teachers' Beliefs; and the Potential of Challenging Existing Beliefs to bring about a change in Practices.

A research examining the Content and Sources of Teacher Candidates' Personal Practical Theories (PPTs) found that such beliefs can influence teachers' classroom practices and, therefore, the opportunities that their students have for learning [5]. A study to examine the student-teachers' epistemological beliefs and conceptions of teaching shows that most of the student-teachers: (i) strongly believed that learning effort was more important than innate ability, (ii) strongly believed that knowledge changes, and (iii) were inclined to question the authority of knowledge[6]. Another research focused on studying teachers' beliefs about their students' preparedness to achieve success in science and the teachers' reported curricular responses to those beliefs [7].

A research study examined the relationship between teachers' beliefs and intentions about the importance of teacher-child interactions. The study revealed that beliefs are predictive of intentions [8]. A study focused on a cohort of teacher candidates who were placed in an urban and culturally diverse practicum site at an elementary school suggest that multiple opportunities across time are needed to uncover and dialogue about beliefs to present significant change rather than single, isolated opportunities [9]. It has been found that pre-service teachers come to a teacher education course with prior experiences, knowledge and beliefs about learning and teaching [10]. The assumption that 
"teachers can easily articulate their beliefs and that there is a one-to-one correspondence between what teachers' state and what researchers think those statements mean has been challenged." "When apparent inconsistencies arise, the framework calls for further elucidation; it calls for a deeper understanding of teachers' beliefs and a better understanding of our inferences as researchers [11]." It is reported that although teachers' core instructional beliefs are difficult to accurately measure, they provide a framework for understanding the thinking that underlies important curricular and pedagogical decisions made in the classroom [12].Researchers have found that teachers' beliefs form a part of the process of understanding how teachers conceptualize their work, which in turn is important to the understanding of teachers' practices and their decisions in the classroom [13]. Teachers with interventionist beliefs about students show more effective practice than teachers with pathognomonic beliefs [14]. That uncovering teachers' beliefs about teaching and learning influence their instructional practices and students' goals in the classroom is important for understanding how to create learning environments focused on mastery and understanding was reported in a study [15]. A study that focused on exploring the beliefs that elementary teachers hold about the teaching and learning of science and the extent to which these beliefs were consistent with the philosophy of current science education reform in United States found that the teachers' beliefs can be summarized in three categories along a continuum- traditional, transitional and nontraditional [16]. Teachers' beliefs regarding developmentally appropriate practices in India, highlights the distinct differences and striking similarities between American and Indian cultures and the importance of culture as the foundation for classroom practice [17]. In another study, the researchers assessed kindergarten teachers' beliefs, stated practices and actual practices regarding developmentally appropriate practices (DAP) in India, and indicated that teachers' beliefs were more developmentally appropriate than their stated practices or actual practices in the classroom. That most teachers perceived the learner to be a knowledge receiver, knowledge as fixed and learning as a process of receiving knowledge was studied [18]. Beliefs of Asian Indian teachers indicate that these teachers lean more toward the use of what westerners view as inappropriate practices and raise the issue of the meaning of developmentally appropriate practices in different countries [19]. Further, it has been found that teaching experience is important, but not necessarily enough to increase teachers' outcome expectancy beliefs [20]. In a paper on Pre-Service Teachers' Beliefs about Teaching English to Primary School Children discuss the idea that teachers' beliefs about English teaching influence their conversations in the classroom [21]. In a research based in Mumbai, beliefs and attitudes of primary school teachers towards children who stutter were studied [22]. It is they believed that children have the potential to overcome stuttering and they accepted the significance of their roles in supporting children who stutter and their responses indicated a desire to support the children. A study conducted in eighteen countries across the world found that discrimination primarily on the basis of ethnicity, socio-economic status and ability is prevalent across different countries [23]. Another study examined the pre-service and in-service teachers' perceptions about the nature of pedagogy and overall beliefs of Science education in relation to the tenets of constructivism [24]. It is evident from the researches discussed above that the study of teachers' beliefs has the potential to provide significant and profound insights into many aspects and perspectives of a teacher's world. The researches in the area reveal that since the relationship between teachers' beliefs and their practices is complex and context dependent, teachers' beliefs and practices need to be examined in their context. The subsequent paragraphs discuss the findings of researches highlighting the contextual factors that influence teachers' beliefs.

The results of a study indicated that "depth of training influences intentions" [25]. Those with the least and most training believed that they were interacting with children most appropriately. Teacher aides felt more able to practice their beliefs than teachers themselves. Another study reported that teacher candidates with multicultural schooling and life experiences are more likely to have favourable beliefs and attitudes regarding cultural diversity than the candidates with mono-cultural schooling and life experiences [26]. The phenomenon whereby student teachers arrive for their training courses having spent thousands of hours as school children, observing and evaluating professionals in action was researched [27]. Teachers' perceptions and beliefs about learner, processes of learning and assessment were found to be influenced by prevailing educational practices which in turn influenced their decision about the classroom. Thus, these affected the ways in which children made a choice of sources and modes to construct their knowledge [28].

A narrative inquiry into teachers' beliefs has been studied within the theoretical frameworks provided by Elbaz and Connelly and Clandin [29]. Prospective teachers' as well as in-service teachers' personal theories of knowledge, learning and learners in the context of the number of years of teaching experience were studied in India that focused the changes in teachers' personal theories as a function of teaching experiences [30]. A paper on Teachers' Beliefs and Teaching Beliefs examines the ways by which teacher educators can change some of the 
beliefs of teachers and teacher candidates early in a teacher education program [31]. An action research study on reflective development at school discussed methodological and pedagogical issues arising from teacher beliefs and expectations [32]. It was concluded from a study on teacher beliefs that a mediated, constructivist and collaborative professional development, that sensitizes teachers to individual learning differences, can increase effective teacher beliefs about students [33]. They further suggested that developing more effective teacher beliefs about learners should become a component of teachers' professional development.

Researchers have examined relations between learning activities of teachers and changes in their beliefs and found that teachers who had changed their beliefs in a direction congruent with the aims of recent educational reforms often reported experimentation with colleagues' teaching methods [34]. A study was undertaken to explore the impact of participation on the beliefs and practices of participants (teacher consultants) [35]. The developments in inclusive education being undertaken in schools in India and suggested that there is not only a need to provide stakeholders with the knowledge and skills for developing inclusive teaching practices, but also a need to challenge existing values, beliefs and attitudes to ensure full participation of all children, in the curriculum and culture of their school settings [36]. The perspective and practices of teachers on their conceptions of inclusion and inclusive education were studied and it was concluded that the concept of inclusion was ambiguous and teachers need to develop a deeper knowledge and understanding of inclusion within the Indian context [37]. Teachers' beliefs and practices regarding teaching English in India were studied and teachers accepted the important position of English in the world [38].It was found that the beliefs of elementary school teachers of English were at variance with their practices of assessment [39]. While they emphasized the need for students to learn to communicate freely in English, they admitted that the primary focus of testing was on writing skills. These studies highlight the need to also understand the barriers to implementing teacher beliefs.

\section{Conclusion}

Reviewing the researches in the area of teacher thinking, it is clear that more research needs to be carried out in India in the area of teacher thinking especially its impact on student learning and its implications for teacher preparation programmes. More importantly the teacher education programmes in India deserve to be given a serious thought both in theory and in practice to be able to produce a reflective group of teachers. More attention needs to be paid to teacher thinking and its relationship to effective teaching in order to improve classroom practices and reduce student dropout. Studies have shown that when student teachers enter the teacher education programmes, they tend to carry certain beliefs and assumptions. Research also suggests that personal theories are the best predictors of individual behaviour, and, in particular, that teacher personal theories influence teachers' perceptions and judgments, which, in turn, affect classroom performance. Research also supports that teachers continue to teach as they themselves had been taught while in school. Formal knowledge about teaching develops from the classes in the Teacher Education Programme that the student undergoes and also from the books etc that the student teachers read related to teaching and learning. "The types of knowledge teachers develop beliefs about, include Content knowledge (subject matter knowledge), Pedagogical knowledge (how to teach, how to create an effective learning experience for students), and Pedagogical content knowledge (how to create an effective learning experience within one specific subject matter) [40]." "Teachers make sense of their complex world and respond to it by forming a complex system of personal and professional knowledge and theories which are described as tacit and unconsciously held assumptions about students, classrooms and the material to be taught [41]." Therefore, studying the beliefs that the teachers hold about themselves, about others, and about the world around them presents an excellent stance from which to understand their behaviour and action. Describing 'personal knowledge' as multicoloured, it is observed, "That this piebald form of personal knowledge lies at the very heart of teaching" [42]. Teachers have also been found to overstate students' affective outcomes at the cost of cognitive ones. It is therefore important that the teacher education programs be structured and planned in ways that help students develop a more balanced perspective about education [43].

\section{References}

[1] Bruner, J., (1996). The Culture of Education. Cambridge: Harvard University Press.

[2] Yero. (2001). Teaching in Mind: How Teacher Thinking Shapes Education. Hamilton, MT: Mind Flight Publishing.

[3] Pajares, M. F. (1992). Teachers' beliefs and Educational Research: Cleaning Up a Messy Construct. Review of Educational Research, 62 (307).

[4] Pajares, M. F., (1992). Teachers' beliefs and Educational Research: Cleaning Up a Messy Construct. Review of Educational Research, 62 (307). 
[5] Levin, \& He, Y. (2008). Investigating the Content and Sources of Teacher Candidates' Personal Practical Theories (PPTs). Journal of Teacher Education, 59 (1), 55-68.

[6] Cheng, M. H., Chan, K., Tang, S. Y., \& Cheng, A. Y. (2009). Pre-service Teacher Education Students' Epistemic Beliefs and their Conceptions of Teaching. Teaching and Teacher Education, 25 (2), 319-327.

[7] Prime, G., \& Miranda, R. J. (2006). Urban Public High School Teachers' Belief about Science Learner Characteristics: Implications for Curriculum. Urban Education, 41 (5), 506-532.

[8] Wilcox-Herzog, \& Ward. (2004). Measuring Teachers' Perceived Interactions with Children: A Tool for Assessing Beliefs and Intentions. Early Childhood Research and Practice, 6 (2).

[9] Kyles, C. R., \& Olafson, L. (2008). Uncovering Preservice Teachers' Belief about Diversity through Reflective Writing. Urban Education, 43 (5), 500-518.

[10] Farrell, T. S. (2006). 'The Teacher Is an Octopus': Uncovering Preservice English Language Teachers' Prior Beliefs through Metaphor Analysis. RELC Journal , 37 (2), 236-248.

[11] Leatham, K. R. (2006). Viewing Mathematics Teachers' Beliefs as Sensible Systems. Journal of Mathematics Teacher Education, 9 (1), 91-102.

[12] Gill, G., \& Hoffman. (2009). Shared Planning Time: A Novel Context for Studying Teachers' Discourse and Beliefs About Learning and Instruction. Teachers College Record, 111 (5), 1242-1273.

[13] Mansour, N. (2009). Science Teachers' Beliefs and Practices: Issues, Implications and Research Agenda. International. Journal of Environmental \& Science Education, 4 (1), 25-48.

[14] Rosenfeld, M., \& Rosenfeld, S. (2007). Developing Effective Teacher Beliefs about Learners: The Role of Sensitizing Teachers to Individual Learning Differences. Educational Psychology , 28 (3), 245-272.

[15] Deemer, S. A. (2004). . 2004. Classroom goal orientation in high school classrooms: revealing links between teacher beliefs and classroom environments. Educational Research , 46 (1), 73-90.

[16] Levitt, K. E. (2001). An Analysis of Elementary Teachers' Beliefs regarding the Teaching and Learning of Science. Science Education, 86 (1)

[17] Hegde, A. V., \& Cassidy, D. J. (2009). Kindergarten Teachers' Perspectives on Developmentally Appropriate Practices (DAP): A Study Conducted in Mumbai (India). Journal of Research in Childhood Education, 23 (3).

[18] Thi, H. N., (2009). A Study of the Processes of Knowledge Construction in Vietnamese Children: A Sociocultural Perspective in Cognition. Delhi University: Unpublished Ph.D Thesis.
[19] Jambunathan, S., (2005). Beliefs about the Importance of Use of Developmentally Appropriate Practices among Early Childhood Teachers in India. Journal of Early Childhood Teacher Education, 26 (3), 275-281.

[20] Josephine, M., Desouza, S., Boone, W. J., \& Yilmaz, Y. O., (2004). A Study of Science Teaching Self-Efficacy and Outcome Expectancy Beliefs of Teachers in India. Science Education, 88 (6), 837-854.

[21] Shinde, M. B., \& Karekatti, T. K. (2012). Pre-Service Teachers' Beliefs about Teaching English to Primary School Children. International Journal of Instruction, 5 (1), 69-86.

[22] Pachigar, V., Stansfield, J., \& Goldbart, J. (2011). Beliefs and Attitudes of Primary School Teachers in Mumbai, India towards Children Who Stutter. International Journal of Disability Development and Education, 58 (3), 287-302.

[23] Curcic, S. (2009). Inclusion in PK-12: An International Perspective. International Journal of Inclusive Education, 13 (5), 517-538.

[24] Khanna, P. (2007). Constructivist Pedagogy in Learning of Science - A Study of Perception of Teacher and Pupil Teachers. Jamia Millia Islamia, Delhi: Unpublished Ph.D Thesis.

[25] Wilcox-Herzog, \& Ward. (2004). Measuring Teachers' Perceived Interactions with Children: A Tool for Assessing Beliefs and Intentions. Early Childhood Research and Practice, 6 (2).

[26] Kyles, C. R., \& Olafson, L. (2008). Uncovering Preservice Teachers' Belief about Diversity through Reflective Writing. Urban Education, 43 (5), 500-518.

[27]Borg, M. (2004). The Apprenticeship of Observation. ELT Journal, 58 (3), 274-276.

[28] Thi, H. N. (2009). A Study of the Processes of Knowledge Construction in Vietnamese Children : A Sociocultural Perspective in Cognition. Delhi University: Unpublished Ph.D Thesis.

[29] Amita. (2010). Understanding Teachers' Beliefs and their Influence on Teaching Learning Process. Delhi University: Unpublished M.Phil Dissertation.

[30]Kalra, M. B. (2012). Teachers Personal Theories of Knowledge, Learning and Learners: Implications for Teacher Education Programmes. Delhi University: Unpublished Ph.D Theisis.

[31] Raths, J. (2001). Teachers' Beliefs and Teaching Beliefs. Early Childhood Research and Practice, 13 (1).

[32] Koutselini, M. (2008). Participatory Teacher Development at Schools: Processes and Issues. Action Research, 6 (1), 29-48.

[33] Rosenfeld, M., \& Rosenfeld, S. (2007). Developing Effective Teacher Beliefs about Learners: The Role of 
Sensitizing Teachers to Individual Learning Differences. Educational Psychology , 28 (3), 245-272.

[34] Meirink, J. A., Meijer, P., Aulien, C., Verloop, N., \& Bergen, T. C., (2009). Understanding Teacher Learning in Secondary Education: The Relations of Teacher Activities to Changes Belief about Teaching and Learning. Teaching and Teacher Education: An International Journal of Research and Studies, 25 (1), 89-100.

[35] Kenreich, T., (2007). Belifes, Classroom practices and Professional Development Activities of Teacher Consultants. Journal of Geography, 103 (4), 153-160.

[36] Singal, N. (2008). Working towards Inclusion: Reflections from the Classroom. Teaching and Teacher Education: An International Journal of Research and Studies, 24 (6), 1516-1529.

[37] Hodkinson, A., \& Devarakonda, C., (2009). Conceptions of Inclusion and Inclusive Education: A Critical Examination of the Perspectives and Practices of Teachers in India. Research in Education, 82 (1), 85-99.

[38] Ramanathan, H., \& Bruning, M. D. (2003). Reflection on Teaching Oral English Skills in India: A Research Report. Journal of the International Society for Teacher education, 7 (1), 48-55.

[39] Ramanathan, H. (2001). Assessment and Testing in an English Classroom in India. Paper Presented t the Annual Meeting of the Mid-Western Educational Research Association. Chicago.

[40] Bruner, J. (1996). The Culture of Education. Cambridge: Harvard University Press.

[41] Kagan, D. M., (1992). Implication of Research on Teacher Belief. Educational Psychologist, 27 (1), 65-90.

[42] Kagan, D. M., (1992). Implication of Research on Teacher Belief. Educational Psychologist, 27 (1), 65-90.

[43] Pajares, M. F., (1992). Preservice Teachers' Beliefs: A Focus for Teacher Education. Florida. 